\title{
Growth performance and wood structure of wavy grain sycamore maple (Acer pseudoplatanus L.) in a progeny trial
}

\author{
Mona Quambusch ${ }^{1,2}\left(\right.$ D $\cdot$ Cornelia Bäucker ${ }^{3} \cdot$ Volker Haag $^{4} \cdot$ Andreas Meier-Dinkel $^{1} \cdot$ Heike Liesebach $^{5}$
}

Received: 20 May 2020 / Accepted: 18 January 2021 / Published online: 17 February 2021

(c) The Author(s) 2021

\begin{abstract}
- Key message Wavy grain, a rare figure type of wood, leads to highly priced timber in Acer pseudoplatanus $\mathbf{L}$. The influence of this trait on growth performance and its causes are not known. Analyzed wavy and straight grain sycamore maple progenies show comparable growth performance in a field trial. Stability of wavy grain after vegetative propagation is confirmed and genetic inheritance indicated.

- Context Wavy grain is a rare figure type of wood resulting from undulating fiber growth that leads to a decorative and highly priced timber in Acer pseudoplatanus L. with top positions on auction sales. Nevertheless, neither the influence of this trait on growth performance is known, nor have the causes been disentangled.

- Aims Our objectives were to find out if wavy grain figure influences growth parameters essential for log quality and to gain insight into the causes of wavy grain by the analysis of a progeny trial and a seed orchard.

- Methods In a progeny trial with 30-year-old F-1-offspring from selected wavy grained and straight grained trees, trunk diameter, tree height, and trunk shape were evaluated. Additionally, 21 trees of the trial and selected plus tree-grafts of a seed orchard were felled and analyzed for occurrence and intensity of wavy grain structure.

- Results No effect of the wavy and straight grain parentage on growth was observed in the progeny trial. Of the felled trees, over $30 \%$ showed evidence of wavy grain compared to rare occurrence in natural stands. Wood structure analysis of plus tree scions confirmed the stability of wavy grain after vegetative propagation.

- Conclusion Wavy grain seems to be genetically inherited, and there seems to be no statistically significant difference in commercially relevant traits in the progeny. This highlights the value of including wavy grain as a desired attribute in breeding systems of maple.
\end{abstract}

Keywords Acer pseudoplatanus $\cdot$ Fiddleback maple $\cdot$ Figured wood $\cdot$ Wavy grain $\cdot$ Progeny test $\cdot$ Growth parameters

Handling Editor: Jean-Michel Leban

Contribution of the co-authors Conceived and designed the experiments: MQ, CB, VH, HL, AMD. Performed the experiments: MQ, CB, VH. Analyzed the data: MQ, CB, VH. Wrote the paper: MQ, CB, VH, HL, AMD.

Mona Quambusch

mona.quambusch@julius-kuehn.de

Cornelia Bäucker

cornelia.baeucker@thuenen.de

Volker Haag

volker.haag@thuenen.de

Andreas Meier-Dinkel

andreas.meier-dinkel@nw-fva.de

Heike Liesebach

heike.liesebach@thuenen.de
1 Abteilung Waldgenressourcen, Nordwestdeutsche Forstliche Versuchsanstalt, Hann. Münden, Germany

2 Julius Kühn-Institut, Institut für Pflanzenschutz in Gartenbau und Forst, Braunschweig, Germany

3 Thünen-Institut für Forstgenetik, Waldsieversdorf, Germany

4 Thünen-Institut für Holzforschung, Hamburg, Germany

5 Thünen-Institut für Forstgenetik, Großhansdorf, Germany 


\section{Introduction}

Some individuals of Acer pseudoplatanus L. exhibit a very special and decorative figure of wood called "wavy" or "fiddleback" grain. Sycamore maple wood is described as creamy white, hard, and can be worked to a very smooth finish (Rusanen and Myking 2003). Due to its poor durability (Krabel and Wolf 2013), the timber is used mostly for indoor purposes, e.g., for furniture making, joinery, and indoor flooring. Besides this, wavy grain maple has been traditionally used for the backs of violins and other string instruments since the mid-sixteenth century (Beals and Davis 1977) and is therefore also known as "fiddleback" maple.

In wavy grain, undulations of the wood fibers in the tree rings result in a systematically changing orientation of cambial cells (Hejnowicz and Romberger 1979). Mainly, the undulations are perceived as a "washboard" effect in the split radial plane and visible on the tangential surface by grain distortion to the left and right every few millimeters (Beals and Davis 1977; Panshin and De Zeeuw 1980). Split and/ or tangential faces of such logs, therefore, show the optical illusion of waves caused by a distinctive pattern of alternating bright and dark stripes shading into one another (Conrad 1988; Beals and Davis 1977; Park et al. 2010). Characteristic for this type of figure is the absence of visible external evidence (Beals and Davis 1977). Examination for wavy grain by removal of the bark is possible (Mayer-Wegelin and Pieper 1959) but leads to wounding of the tree resulting in a reduction of wood quality and raising the risk of fungal infections.

Although this figure deviates from normal straight grain, it often greatly enhances the value of the wood making wavy grained A. pseudoplatanus one of the most highly priced timbers on the market. Maple logs with a regular, well-developed wavy grain structure are usually sold at auction sales, so-called submissions, often for more than the tenfold price of similar logs with straight grain. In Germany, wavy grained sycamore maple regularly achieve prices over 10,000 Euro per log, e.g., 12,100 Euro at the submission Waging in 2017 (Bäucker and Liesebach 2018) and 19,602 Euro (equivalent to 7748 Euro per $\mathrm{m}^{3}$ wood) in Jesberg in 2017 (HessenForst 2017).

The fiddleback figure may be observed over the geographic range of $A$. pseudoplatanus with frequencies up to $7 \%$, sometimes with local concentrations independent of site conditions (Conrad 1988; Krajnc et al. 2015). The reasons for the formation of wavy grain are still unknown (Naujoks et al. 2013; Ewald and Naujoks 2015). Some have suggested a connection between similar figured grains and genetics. Several observations point to a genetic link and the possible heritability of the trait. For example, Conrad (1988) describes a radial section of a graft union showing clear wavy grain at one side and straight grain at the other side of the union.
Several attempts were made to develop hypotheses on the formation of different kinds of figured wood, including its link to genetics. Fan et al. (2013) analyzed grafts of figured aspen and found that both scion and rootstock retained the properties of the original tree. Moreover, they could exclude graft-transmissible signals like plant hormones and RNAs as the cause of wavy grain figure and reported direct evidence for the inheritance of figure in aspen, whereby the segregation ratio indicates a complex genetic regulation (Fan et al. 2013). Further evidence for genetic inheritance of figure in wood has been published by Kärkkäinen et al. (2017) for curly birch. They postulate a simple Mendelian inheritance model for the curliness with one semi-dominant locus based on the analysis of comprehensive offspring families from crossings of curly and straight birch trees. For black walnut, in contrast, McKenna et al. (2015) found only weak indication for genetic control of figure in their analysis of both grafts and open pollinated progeny. Hence, they concluded that environmental factors appear to play a substantial role in the formation of commercially valuable figured grain.

To our knowledge, there is no published study on the inheritance of wavy grain figure in sycamore maple. The figure types studied in other trees species (Fan et al. 2013; McKenna et al. 2015; Kärkkäinen et al. 2017) show similarities but are not identical to the narrow and regular undulations seen in fiddleback figure of A. pseudoplatanus. Several reasons lead to the limited knowledge despite the commercial interest in this trait. Some examples show that the fiddleback figure can be assessed after 10 or more years of growth (Conrad 1988; Ewald and Naujoks 2015; McKenna et al. 2015), and felling of the tree is needed for a detailed evaluation of the intensity of figure formation. Wavy grain is rarely considered an important trait for the selection of plus trees during the establishment of seed orchards (Krabel and Wolf 2013). Instead, the selection criteria used in most European countries for A. pseudoplatanus were focused on growth and tree architecture. Wood quality in general and wavy grain structure in particular were not part of a breeding program, although both traits were considered in very few instances in France and Germany (Krabel and Wolf 2013).

The only experimental sites capable of conducting an analysis of heredity of wavy grain in maple to our knowledge exist at the Northwestern German Forest Research Institute. One site is an A. pseudoplatanus seed orchard with 60-yearold grafts of both figured and unfigured plus trees located in Reinhardswald, Hessen, Germany. Two further sites exist in Romrod and Schotten (Hessen, Germany), where progeny trials with open pollinated offspring of the seed orchard clones were established in 1986. With these 33-yearold trees of the F1 generation, we addressed the following questions: (1) Does fiddleback figure, as a selection criterion for plus trees of a seed orchard, negatively influence growth parameters that are essential for their log quality in the 
offspring? (2) Is the wavy grain structure conserved in the scion of the grafts in the seed orchard? (3) Is the incidence of fiddleback figure higher in the offspring of the progeny test than in natural populations?

\section{Materials and methods}

\subsection{Experimental sites}

The basis for our analysis was an old seed orchard of $A$. pseudoplatanus in the forestry district Reinhardshagen in Hessen, Germany. Selection criteria for the 21 plus trees included stem form and growth performance; in addition, seven of them had wavy grain figure and two had birdseye figure. Scions of the plus trees were grafted onto seedling rootstocks of A. pseudoplatanus, and 28 grafts of each plus tree were planted from 1959-1964 in a single tree completely randomized design with $5 \times 5 \mathrm{~m}$ spacing. The seed orchard was thinned and trees felled in 1985 and, in 2015, where rootstocks, which had developed and grew instead of scions, were eliminated based on a former isoenzyme identity check.

In 1986, a progeny trial was established at two experimental sites in the forest districts Romrod and Schotten in Hessen, Germany. Both sites have eutrophic soil with basalt as parent material and a covering of silty loam and loam-loess. Open pollinated seeds were harvested from the seed orchard grafts of 13 plus trees, five from wavy grain clones (namely Gö16, Me4, Me6, Me7, Me10), six from straight grain clones (namely Gö3, Gö4, Gö5, Me1, Me3, Sal3), and two from birdseye grafts (Gö2, Gö15). Seedlings of three standard seed sources from the forest departments Wolfgang and Hofbieber (Hessen, Germany) were additionally included (namely Wo1, Wo2, Ho1). The 2-yearold seedlings $(1+1)$ were planted with $2.5 \times 1.5 \mathrm{~m}$ spacing in plots of 16 with 3 to 4 replicates in each experimental site.

\subsection{Tree growth: data collection and statistical analysis}

In January 2017, growth parameters and Kraft tree classes of the progeny trials were evaluated. To determine the diameter at breast height (DBH), the tree trunk was manually measured at $1.30 \mathrm{~m}$ height in two directions with a caliper and the mean was used for the analysis. For the measurement of tree height, Vertex III and Transponder T3 (Haglöfs, Langsele, Sveden) were used to obtain the exact distances via ultrasonic signals and to calculate the tree height trigonometrically with the distance and angle variables. The shape of the trunk was assessed on about $3 / 4$ of the tree height beginning from the ground and was rated on a scale from 1 to 5 as follows: (1) absolutely straight, (2) fairly straight (lightly crooked in one direction), (3) slight to moderate bends in more than one direction, (4) moderate to strong bends, and (5) being very crooked.

In total, data were obtained for 560 trees at the Romrod site and 509 at the Schotten site. Progenies of the following plus trees were excluded from the analysis for different reasons: due to birdseye figure (Gö2, Gö15), inconsistent information on the figure (Gö16), and wrong identity of the harvested seed (for Gö3 and Me1 existence of flowering rootstocks instead of scions was revealed by microsatellite analysis). Further, offspring of Gö4 and Me3 were missing at the experimental site in Schotten due to a lack of seedlings. Of the remaining, 155 and 169 trees were categorized as fully vital (corresponding to Kraft tree classes 1-3) at the Romrod and Schotten experimental sites, respectively, and included into the analysis. Strongly suppressed trees (Kraft tree classes 4 and 5, 3-14 cm in diameter) were excluded from the analysis to avoid their strong influence on the measures of growth performance.

Statistical analysis was conducted with the program $\mathrm{R}$ version 3.6.0 (Development Core Team R 2019). Using the Ime function in the nlme package of R (Pinheiro et al. 2019), linear mixed effect models (LMMs) were parameterized with the available data. The response variables DBH, tree height, and trunk shape were tested for significant differences between offspring families, which were defined as fixed effect. The replication within the trial design (block and experimental site, nested) was chosen as the random effect. The model assumptions of normality and homoscedasticity were tested using the Shapiro-Wilk test and Levene's test, respectively, using the package car (Fox and Weisberg 2011). The results were confirmed by examination of residual plots. After establishing that the assumptions were not violated, an omnibus test (here F-test) was used to determine if any significant differences exist for the response variables by the factor "offspring family." If the null hypothesis was rejected, pairwise comparisons of estimated marginal means (Tukey's test) were applied using the package emmeans (Lenth 2019). The differences between offspring families and groups were quantified and tested for statistical significance by their means. The same procedure as for the comparison of offspring families was applied to the comparison of the groups "standard seed stand," "plus tree mother with straight grain," and "plus tree mother with wavy grain," and for the groups "standard seed stand" and "plus tree offspring." For the trunk shape data, we worked with single tree data instead of plot means, used the Kruskal-Wallace test for non-parametric data and performed the pairwise comparisons with Dunn's test to account for the ordinal scale of the data. The significance level was set as $a=0.05$ for all tests.

\subsection{Analyses of wavy grain presence and intensity}

For the investigation of the wood structure, 21 trees of the progeny trial were felled at the experimental site Romrod 
in January 2017. The trees were randomly selected and contained three trees of each plus tree progeny, each belonging to a different plot. Additionally, four reference samples were harvested from the original plus tree grafts at the seed orchard Reinhardshagen. For a detailed documentation of the wood anatomy and structure development during the wood formation, stem parts of about $1 \mathrm{~m}$ in length were taken above the root system and, depending on the individual growth, in higher stem parts, up to a height of $9 \mathrm{~m}$.

Fresh stem sections were divided into four segments along the trunk axis and afterwards air-dried for about 6 months. The dried pieces of wood were then further reduced in their sizes to about $2.5 \mathrm{~cm}$ thickness whereby the boards were radially oriented and sawed by tangential section.

Determination of the wavy grain expression was carried out in two stages. First, the radial wood surfaces were visually inspected for the characteristic strips. Second, the tangential surfaces were examined macroscopically with a hand lens for presence of the characteristic s-shaped structure. In case of doubt, additional wood samples were sectioned with a sliding microtome for detailed microscopic examination.

Additionally, tangential sections of around $20 \mu \mathrm{m}$ thickness of air-dried wood samples were cut sequentially with a sliding microtome. The sections where stained with safranin and astra blue and mounted in synthetic resin (Euparal). A digitized image analysis system (analySIS ${ }^{\circledR}$, Olympus) mounted on an Olympus AX 70 microscope was used for the structural analysis and documentation.

Always investigating the surface of the tangential section of the sample, four categories of wavy grain intensity were defined. These categories directly refer to the visible amount of wood surface characterized by wavy grain structure:

(i) high intensity with $60-100 \%$ wood surface exhibiting wavy grain

(ii) medium intensity with $30-60 \%$ wood surface exhibiting wavy grain

(iii) low intensity with $10-30 \%$ wood surface exhibiting wavy grain

(iv) no presence of the regular wavy grain pattern; minimal discrepancies $(<10 \%)$ from straight grain might occur

The four categories are schematically shown in Fig. 1.

\subsection{Genotyping and parentage analysis}

Different types of plant material were sampled for DNA extraction: dormant buds, leaves, and cambium. The buds were stored at $-20{ }^{\circ} \mathrm{C}$, leaf and cambium material was airdried. The buds were harvested from all 21 parental clones

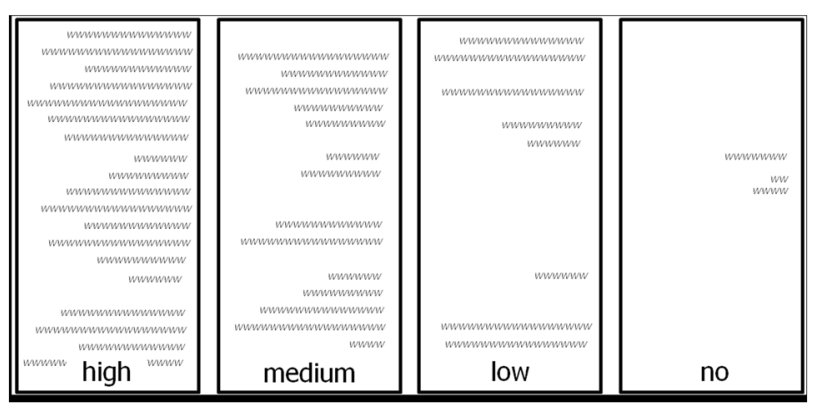

Fig. 1 Classification system of wavy grain intensity in A. pseudoplatanus based on wood samples of $1 \mathrm{~m}$ length. In category "no" wavy grain, minimal discrepancies from straight grain might occur

at the seed orchard Reinhardshagen in December 2016. Bud samples were also taken from the 21 trees felled at the progeny field test in Romrod. From all other progenies growing in Romrod and Schotten, we collected leaf samples in July 2017. If leaves could not be reached by using a $10 \mathrm{~m}$ pruning shear, cambium samples were taken. To ensure that the correct trees were sampled at the field trials, we used both information from the trial layout of the progeny tests and measurements of DBH from the last documentation in January 2017. DNA of buds, leaf material, and cambium was extracted according to the protocol by Dumolin et al. (1995) with minor modifications.

The individual genotyping method is based on 12 nuclear SSR markers, which were known from the literature: MAP2, MAP9, MAP12, MAP33, MAP40 (Pandey et al. 2004), Am118 (Kikuchi and Shibata 2008), Aop116, Aop122, Aop943 (Segarra-Moragues et al. 2008), SM21A, SM29, and SM60 (Graignic et al. 2013). Detailed laboratory techniques are published by Bäucker and Liesebach (2018).

For parentage analysis, the software program COLONY (Jones and Wang 2010; Wang and Scribner 2014) was applied using microsatellite data from the genotypes of the seed orchard in Reinhardshagen (parental generation) and all genotypes of Romrod and Schotten (both progeny tests, F1 generation). Therefore, the results presented here for the 21 felled trees, were calculated in the context of a more comprehensive study including all progenies sampled (Bäucker et al. in preparation).

\section{Results}

\subsection{Growth performance from offspring families with and without wavy grain mother}

Since no significant differences in height and diameter between offspring families were detected within each group (for result data see Figs. 6 and 7 in the Appendix for height and diameter, respectively), this factor was excluded for the 
group comparisons. For the trait DBH, progenies of standard seed stands, of the straight grain mother trees, and of the wavy grain mother trees differed significantly from each other (ANOVA: $p=0.005$ ). The DBH of both wavy grain progeny (mean $194 \mathrm{~mm}$ ) and straight grain progeny (mean $202 \mathrm{~mm}$ ) was bigger than the standard (mean $184 \mathrm{~mm}$ ), the difference being significant in pairwise comparison of the latter ( $p=0.003)$ (Fig. 2a). The height of the tree groups was similar for straight grain $(195 \mathrm{dm})$ and progeny (196 dm) (Fig. 2b). Standard trees were in average higher compared to the other groups, but the difference was not significant (Fig. 8, Appendix). Comparing the two experimental sites, the DBH was bigger in Romrod by $9 \mathrm{~mm}$ on average, while trees in Schotten were in average $10 \mathrm{dm}$ higher (as shown in Figs. 6 and 7, Appendix). The survival rate over all trees was $58 \%$ and did not differ significantly between the sites (51\% and $66 \%$ in Romrod and Schotten, respectively).

A comparison of the shape of the trunk did also show no significant differences between the three groups (ANOVA, $p=0.199)$. The offspring families differed significantly in their trunk shape (ANOVA, $p=0.0001$ ) with standard Wo1 and plus tree offspring Me10 performing significantly better than plus tree offspring Me3 and Me4 as depicted by the percentage of trunk shape rating Fig. 3). Overall, the trunk shape in standards compared to offspring of plus trees did not differ significantly $(p=0.076)$.

In summary, the measured differences within the plus tree progenies were very small, and no aberrant growth of the wavy grain progeny could be observed. As expected, the summed progeny of plus trees, which were in the majority selected for shape and dimensions, had a clearly significant

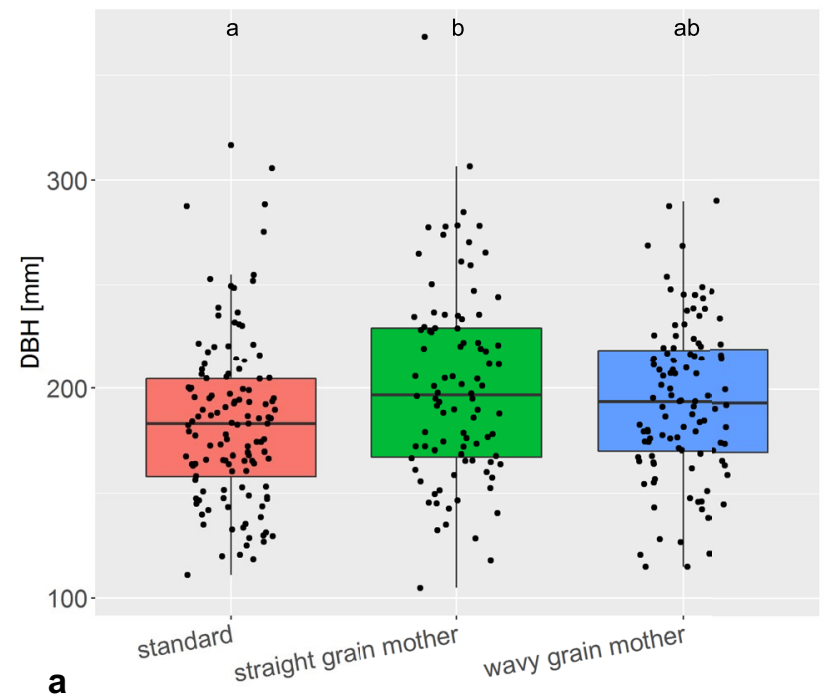

Fig. 2 Comparison of the groups, "standard seed stand", "plus tree mother with straight grain," and "plus tree mother with wavy grain" of the A. pseudoplatanus progeny trials Romrod and Schotten. a DBH. b Tree height. Boxplot with additional information on single higher DBH than standard seed stands $(p=0.0008)$ (Fig. 8, Appendix). Within offspring families, a high level of variability between single trees was observed and no significant differences between families were calculated (ANOVA, $p>0.05$ ) (Figs. 6 and 7, Appendix).

\subsection{Wood structure from selected stems}

Figure $4 \mathrm{a}$ and $\mathrm{b}$ show exemplarily images of the surfaces of A. pseudoplatanus samples. The surface of sample 1.1 plus tree clone Me6 (60-year-old tree) displays a "high" amount of wavy grain structure (Fig. 5a) with very intensive expression due to the age of the wood (mature wood), and the presence of "elephant skin" (in German "Wimmerwuchs"), which is another phenomenon of wood structure (see "Discussion"). In comparison to the mature wood the surface of sample 10A (progeny of Me 6/juvenile wood) also shows "high" intensity of wavy grain but with less intensive expression due to the young age of the tree (30 years) (Fig. 5b).

Three out of four wood samples of plus tree grafts clearly showed the characteristics of the wavy grain structure, whereby the wavy grain intensity ranges from low to high (Table 1). Me6 showed a distinct wavy grain structure with high intensity in all investigated stem portions between 2 and $6 \mathrm{~m}$ height. In contrast, Gö10 and Me4 showed a significantly lower intensity of the wavy grain structure and no wavy grain structure found in Gö16.

When comparing wavy grain intensity between samples from different heights in a single tree, no significant differences could be observed for Me6 and Gö10. For

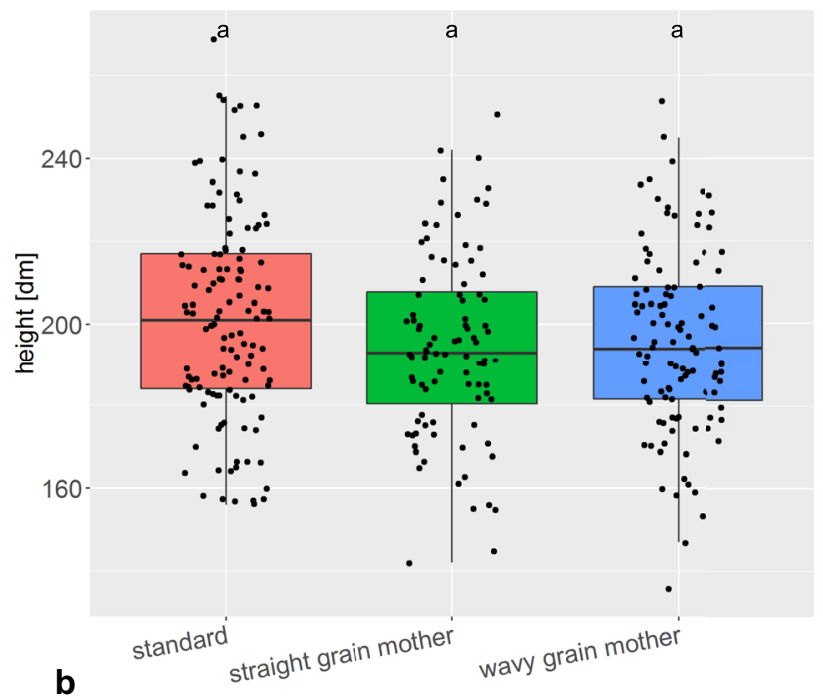

tree data (black dots); $n=125,92,107$ (left to right). Different letters indicate significant differences in pairwise comparison of the groups (Tukey's test, $p<0.05$ ) 
Fig. 3 Rating of the trunk shape of the 30-year-old trees of $A$. pseudoplatanus growing at the progeny trial sites (Romrod and Schotten). $X$-axis shows the plus tree offspring family or harvested standard seed stand (control), respectively. $Y$-axis: percentage of trees rated with each level for the trunk shape. Different letters indicate significant differences in pairwise comparison of the offspring families (comparison of single tree data; Dunn's test, $p<0.05$ )

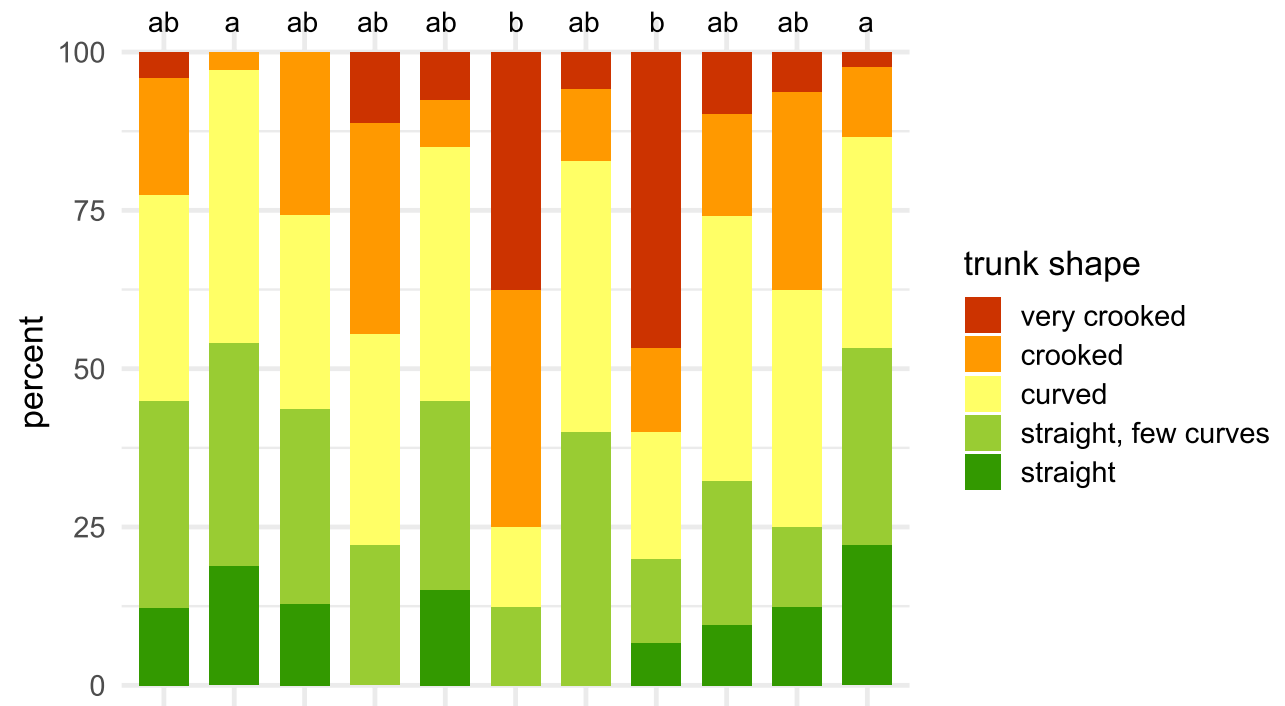

Ho1 Wo1 Wo2 Gö4 Gö5 Me3 Sal3 Me4 Me6 Me7 Me10
Me4, however, samples taken from lower stem portions (two meter) showed significantly more pronounced wavy grain intensity than samples from heights of 3.5 and $6 \mathrm{~m}$. In summary, the plus tree selection criterion "wavy grain" could be confirmed for Me6, Gö10, and Me4 validating the long-term expression of wavy grain by vegetative propagation through grafts over 50 years.

\subsection{Parentage analysis and wood structure from selected offspring}

For 14 out of the 21 felled offspring trees, clear parental combinations are identified using their genotypes (Table 2; no. 1, 2, 4, 5, 7, 9, 10, 12, 15, 16, 17, 18, 19, and 21). For these combinations, the documented mother is always confirmed by one of the proposed parental candidates, except for tree no. 5. Here, the mother correlates to the parental genotype of Me7 instead of Me4. For an additional offspring individual, the mother is also confirmed by the analysis, but the father is unknown (no. 6). Four trees, conversely, have an unknown mother, while a father is estimated from the parental candidates (no. 3, 8, 13, and 14). Further, unknown parents are detected for two progenies (no. 11 and 20).

Overall, the genotypes of Me4, Me6, Me7, Gö4, and Gö16 are verified by at least one clear parental combination. The results for genotype Me1, which has been detected as father in two parental combinations (no. 16 and 4) but not as mother, give a hint for some developed rootstocks instead of scions. The probabilities for calculated parental combinations always tend to be $100 \%$ (Table 2).

Seven out of the 21 felled trees clearly show the characteristics of the wavy grain structure as illustrated in Fig. 1, whereby the wavy grain intensity ranges from low to high (Table 2). A relationship between the existence/intensity

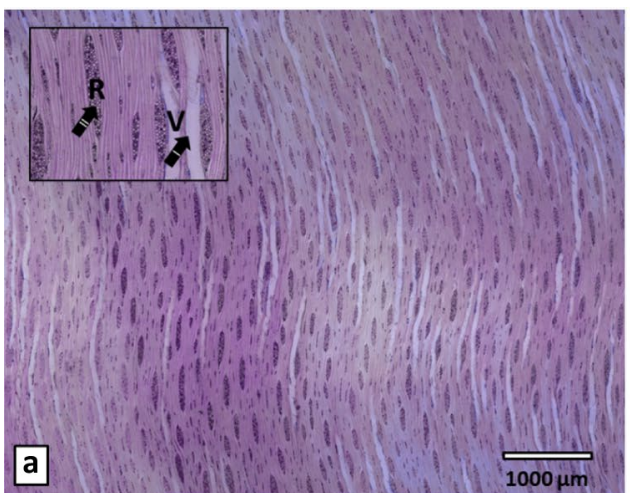

Fig. 4 A. pseudoplatanus. a Microscopic image stained with safranin red and Astra blue displaying the S-shaped structure of wavy grain; box shows area with vessel elements (V/arrow I) and rays (R/arrow II) in higher magnification. b 3D scanning image with polished trans-

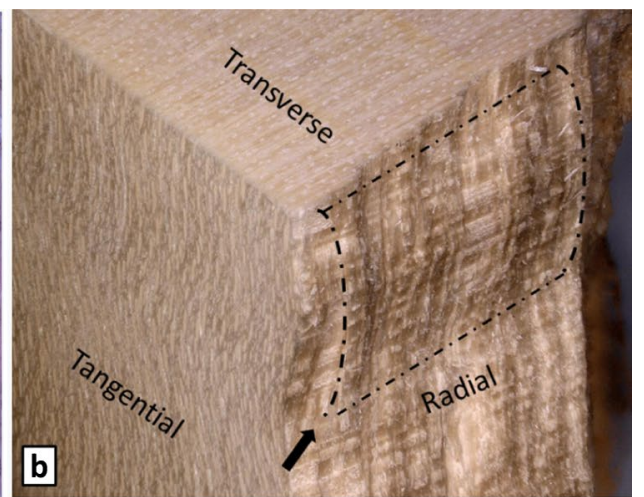

verse section (transverse), tangential section (tangential), and cracked (split) radial section (radial) with schematic emphasis of one wavy grain amplitude (image: S. Kaschuro) 
Fig. 5 Wood samples of Acer pseudoplatanus. a Sample 1.1 of plus tree clone Me6 with "high" amount of wavy grain in mature wood. b Sample 10 A (progeny of Me10) with also "high" amount of wavy grain in juvenile wood

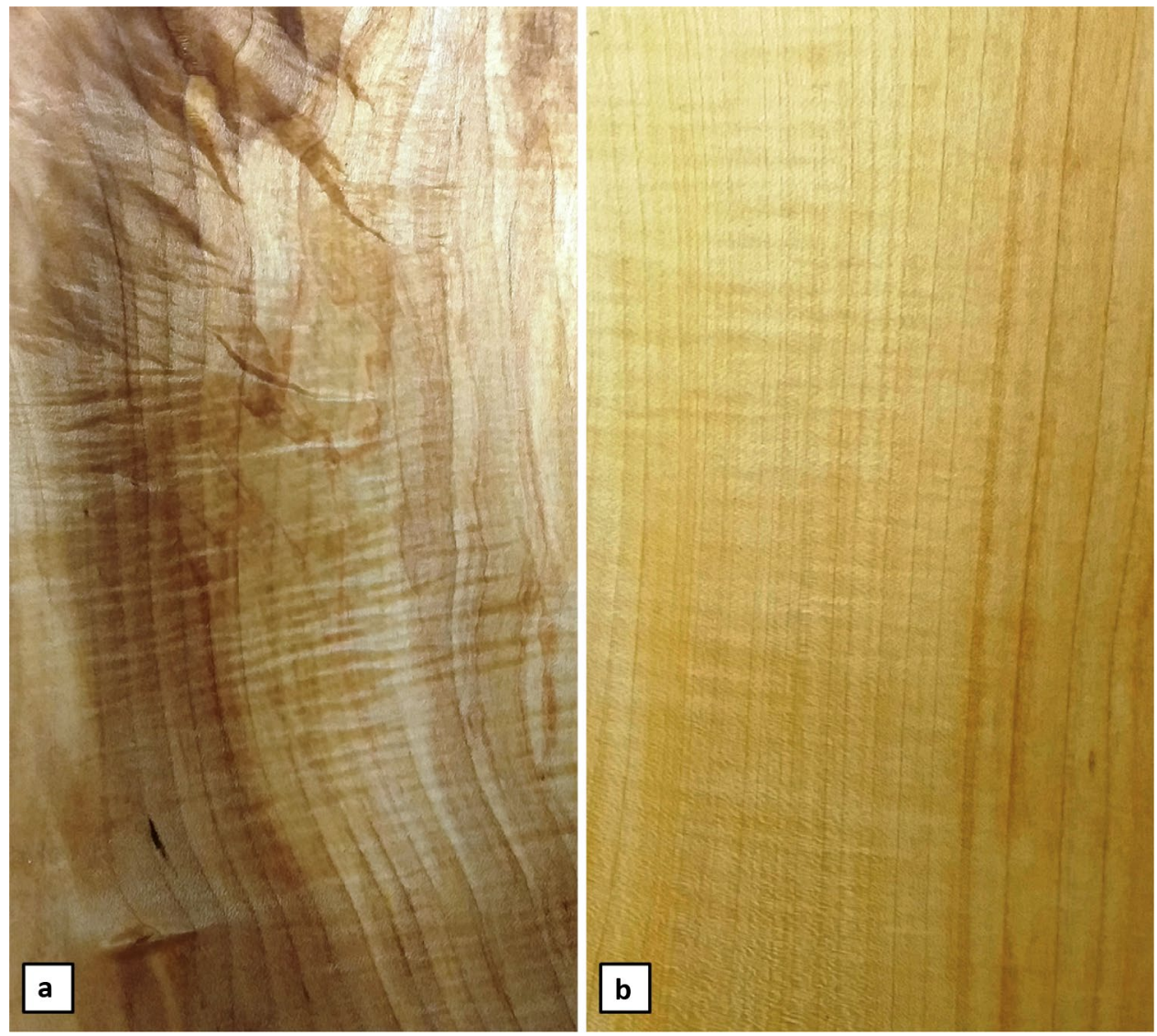

of wavy grain structure in parents and their progenies is difficult to find, because seven out of the 21 trees are assigned to parental candidate/s with unknown grain orientation (Table 3, parents \#). Therefore, we primarily focus on the 14 trees which have parent pairs of defined wood structure.

Here, tree no. 9, which solely is assigned to a wavy grained parent pair, exhibits wavy grain structure of low

Table 1 Results of the macroscopic and microscopic investigation of grafted mature plus trees

\begin{tabular}{llllll}
\hline Sample no. & Plot & Clone & $\begin{array}{l}\text { Height in } \\
\text { tree }(\mathrm{m})\end{array}$ & $\begin{array}{l}\text { Wavy grain } \\
\text { structure } \\
\text { present }\end{array}$ & $\begin{array}{l}\text { Wavy } \\
\text { grain } \\
\text { intensity }\end{array}$ \\
\hline 1.1 & 511 & Me6 & 6 & Yes & High \\
$1.1 \mathrm{a}$ & 511 & Me6 & 2 & Yes & High \\
$1.1 \mathrm{~b}$ & 511 & Me6 & 3 & Yes & High \\
$1.1 \mathrm{~d}$ & 511 & Me6 & 6 & Yes & High \\
2.1 & 414 & Gö10 & 3 & Yes & Low \\
$2.2 \mathrm{~b}$ & 414 & Gö10 & 1.5 & Yes & Low \\
3.1 & 5 & Gö16 & 2 & No & - \\
$3.1 \mathrm{~b}$ & 5 & Gö16 & 6 & No & - \\
$3.1 \mathrm{c}$ & 5 & Gö16 & 9 & No & - \\
4.1 & 210 & Me4 & 6 & Yes & Low \\
$4.1 \mathrm{~b}$ & 210 & Me4 & 2 & Yes & High \\
$4.1 \mathrm{c}$ & 210 & Me4 & 3.5 & Yes & Low \\
\hline
\end{tabular}

intensity. Similarly, four out of the eight trees with the parental combination of wavy grained mother and straight grained father, show low wavy grain intensity (no. 1, 15, 19, and 21), while the other four progenies indicate straight grain (no. 5, 7, 17, and 18). As expected, no indications for wavy grain structure were found for tree no. 4 , which has a straight grained mother as well as father.

The progeny with the most pronounced wavy grain structure is tree no. 10 (high intensity), which represents offspring of a wavy grained mother and straight grained father. For tree no. 14, a medium intensity of wavy grain was detected. Here, the father is straight grain and the mother unknown.

\section{Discussion}

The wavy grain figure in A. pseudoplatanus is only one among several figure types with diverse morphological origin, e.g., birdseye figure, spiral growth, blister, and quilted figure (Beals and Davis 1977). For all these figure types, only few published data exist on the physiological background of the formation and the inheritance. Additionally, the wavy grain structure may appear at the same time as the above-named structural anomalies and its simultaneous occurrence can increase the optical effect. Furthermore, the misinterpretation of other structural 
Table 2 Parental combinations and wood properties of the 21 felled progeny trees. Classification of wavy grain intensity resulted from macroscopic and microscopic investigations. Parental combinations were derived from genotypes. Unknown parents are indicated with "\#," parental clones with wavy grain figure are written in italics. The column "Mother documented" specifies the mother as listed in the trail layout

\begin{tabular}{|c|c|c|c|c|c|}
\hline $\begin{array}{l}\text { No. of tree } \\
\text { felled }\end{array}$ & $\begin{array}{l}\text { Mother } \\
\text { documented }\end{array}$ & Mother identified & Father identified & $\begin{array}{l}\text { Probability of } \\
\text { parental combina- } \\
\text { tion }\end{array}$ & $\begin{array}{l}\text { Intensity of } \\
\text { wavy grain } \\
\text { structure }\end{array}$ \\
\hline 1 & Me6 & Me6 & Gö5 & 1.000 & Low \\
\hline 2 & Gö16 & Gö16 & Me10 & 1.000 & - \\
\hline 3 & Me1 & $\#$ & Me6 & 1.000 & - \\
\hline 4 & Gö4 & Gö4 & Me1 & 1.000 & - \\
\hline 5 & $M e 4$ & $M e 7$ & Gö2 & 1.000 & - \\
\hline 6 & $M e 7$ & $M e 7$ & $\#$ & 1.000 & - \\
\hline 7 & Me10 & Me10 & $\mathrm{Me} 3$ & 1.000 & - \\
\hline 8 & Me1 & $\#$ & Gö4 & 1.000 & - \\
\hline 9 & $M e 7$ & $M e 7$ & Me4 & 1.000 & Low \\
\hline 10 & Me10 & Me10 & Gö5 & 1.000 & High \\
\hline 11 & $\mathrm{Me} 4$ & $\mathrm{Me} 4$ & $\#$ & 1.000 & - \\
\hline 12 & Gö16 & Gö16 & $\mathrm{Me} 2$ & 1.000 & - \\
\hline 13 & Gö4 & $\#$ & Sal3 & 1.000 & - \\
\hline 14 & Me1 & $\#$ & Sal3 & 1.000 & Medium \\
\hline 15 & $M e 4$ & Me4 & Gö12 & 1.000 & Low \\
\hline 16 & Gö16 & Gö16 & Me1 & 1.000 & - \\
\hline 17 & Me6 & Мe6 & $\mathrm{Me} 3$ & 1.000 & - \\
\hline 18 & Мe6 & Me6 & Gö15 & 0.9985 & - \\
\hline 19 & $M e 7$ & $M e 7$ & Gö5 & 1.000 & Low \\
\hline 20 & Gö4 & \# & $\#$ & 1.000 & - \\
\hline 21 & Me10 & Me10 & Gö5 & 1.000 & Low \\
\hline
\end{tabular}

anomalies as wavy grain often led to confusion. It is important to distinguish wavy grain from the so-called elephant skin which frequently occurs at the base of the trunk or at the stem under huge branches. In contrast to wavy grain, elephant skin is visible on the stem surface, less uniform, and does not spread over the whole log as wavy grain or fiddleback does (Richter 2015); Fig. 5a shows a combination of both wood anomalies. In the present study, wavy grain is evaluated exclusively as an S-shaped structure along the tangential surfaces as shown in Fig. $4 \mathrm{~b}$.

Regarding the comparison of growth performance, no effect of the wavy and straight grain parentage could be observed. Significant differences were only measured between single offspring families and between the groups of plus tree offspring compared to standard seed stands. Overall, the results on growth parameters suggest an inverse relationship between DBH and tree height in the sycamore maple trees, with thicker and smaller trees in Romrod and thinner and higher trees in

Table 3 Number of progenies counted for the different combinations of parental wood types. The term "unknown" is used for parents with unknown grain orientation, due to pollen flow from outside

\begin{tabular}{lllll}
\hline & \multicolumn{3}{l}{ Mother's wood type } \\
\cline { 3 - 5 } & Wavy grain & $\begin{array}{l}\text { Straight } \\
\text { grain }\end{array}$ & Unknown \\
\hline Father's & Wavy grain & 1 & 1 & 1 \\
wood type & Straight grain & 9 & 3 & 3 \\
& Unknown & 1 & 0 & 2
\end{tabular}

Schotten. As the soil composition and exposition are very similar between the sites, the difference in stand productivity could be a result from higher water availability as is documented for the experimental sites. Due to small interspace between the 30-year-old trees (min. $1.5 \mathrm{~m}, 58 \%$ survival rate) the high density and competition has to be considered to have an impact on the progeny trial outcome. To our knowledge there are no published studies on the influence of wavy grain on growth parameters of A. pseudoplatanus. Sopushynskyy and Teischinger (2013) reported a 8-16\% larger DBH for ash (Fraxinus excelsior) trees with wavy grain structure compared to those with straight-grained wood in a comparison of selected trees of three experimental forest stands. The result is comparable only to a limited extend due to the different tree species and the age of the investigated trees (80-92 years).

Our results on the occurrence and intensity of wavy grain structure in 21 felled progenies point towards genetic inheritance of the trait wavy grain, because one third of the felled trees show evidence of wavy grain. Also, the observation of stability of wavy grain figure 50 years after grafting (this study) or after tissue-culture propagation (Rohr and Hanus 1987; Ewald and Naujoks 2015) support a genetic cause. Moreover, no reports on a loss of wavy grain figure after any kind of vegetative propagation could be found. A conclusive statement, with regard to the mode of inheritance, is difficult to express on the basis of these 21 individuals, since for 7 trees the grain orientation of one or both parental 
candidate/s is unknown. More research is needed to determine the mode of inheritance and potential genes participating in the physiological mechanisms of wavy grain wood formation.

Studies on other figure types and in other tree species regarding vegetative propagation and genetic inheritance of the figure can be consulted for the classification of wavy grain with regard to management objectives. For birdseye maple, for example, Bragg et al. (1997) state that management practices can have an effect on the development of the occurrence of figured trees in a forest stand. Fan et al. (2013) introduced curly poplar as a model system to broaden the knowledge on heritability and reproducibility of figured wood. The most progress towards targeted use of figured trees in breeding was achieved in curly birch with established protocols for vegetative propagation by tissue culture (Ryynänen and Ryynänen 1986), the establishment of specialty plantings of curly birch and explicit management practice advice for curly birch stands (Hynynen et al. 2010). These findings, in addition to our results on stability and inheritance of the trait, suggest a more targeted use of wavy grain maple in the breeding of sycamore maple.

\section{Conclusion}

Wavy grain seems to be inherited to the offspring, and the progeny is not negatively affected in commercially relevant traits. Maximizing the economic potential of harvestable goods facilitates longer rotation times, allows for more costly harvesting techniques, and thereby minimizes negative impacts on the environment (Bragg 2006). As wavy grain leads to a profound increase in value of the timber, it is recommendable to implement this trait in breeding systems. This could either be achieved by including wavy grain plus trees in $A$. pseudoplatanus seed orchards in mixture with straight grain plus trees to preserve or increase the percentage of wavy grain in forest stands or by selection of a set of vegetatively propagated wavy grain clones with optimal stem characteristics for specialty plantings. Even if successful integration of wavy grain in breeding systems would make it somewhat more frequent, wavy grain maple will remain a valuable timber, supporting the proposed targeted measures.

\section{Appendix}

\section{Results for the different open pollinated offspring families regarding the two experimental sites}

Fig. 6 Tree height of the single progenies of the two progeny trial sites Romrod and Schotten with 30-year-old trees. Boxplot with additional information on single tree data (black dots). No significant differences in pairwise comparison of the progenies (block means) were found (Tukey's test, limit $p<0.05$ )

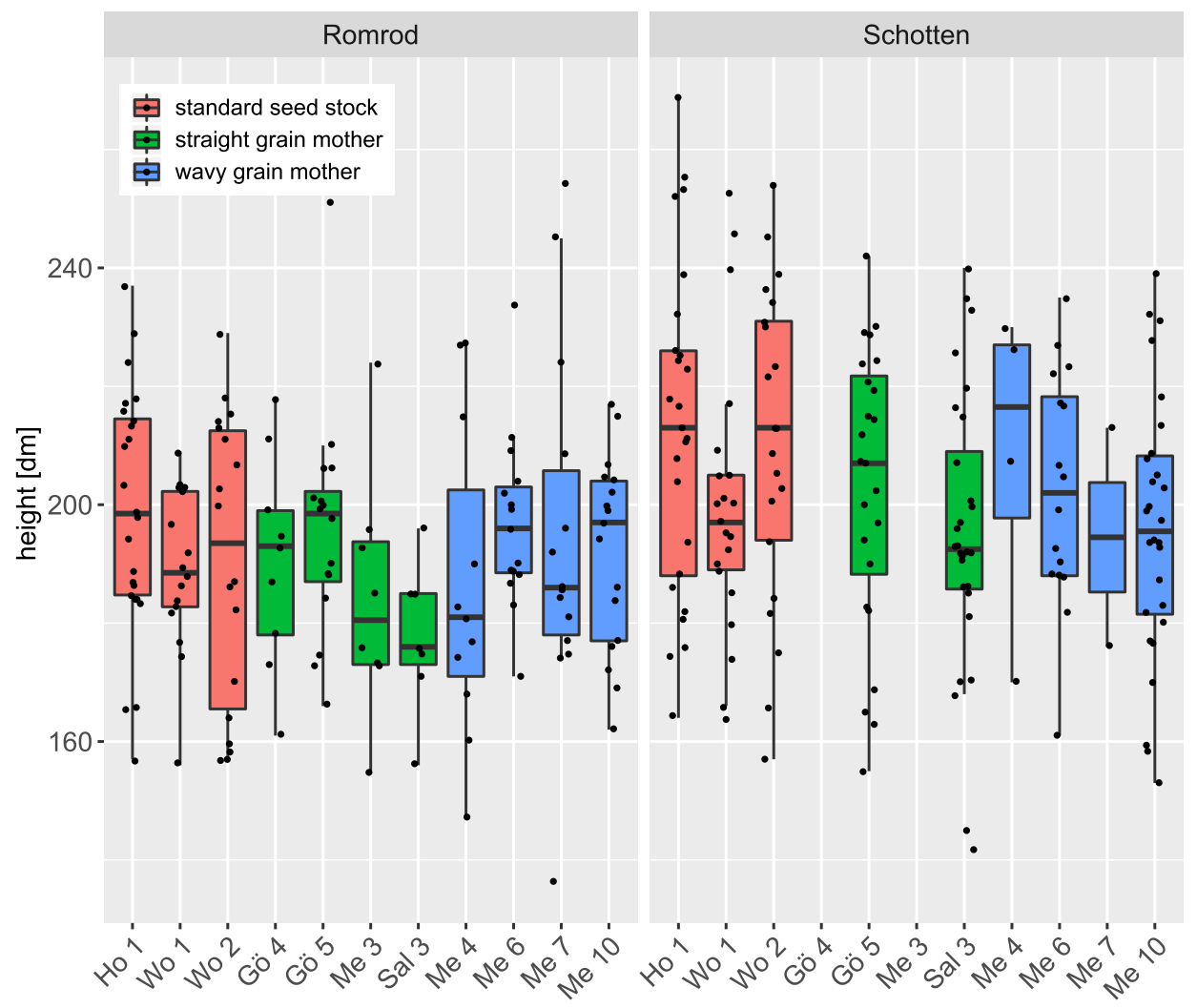


Fig. 7 Tree diameter of the single progenies on the two progeny trial sites Romrod and Schotten with 30-year-old trees. Boxplot with additional information on single tree data (black dots). No significant differences in pairwise comparison of the progenies (block means) were found (Tukey's test, limit $p<0.05)$

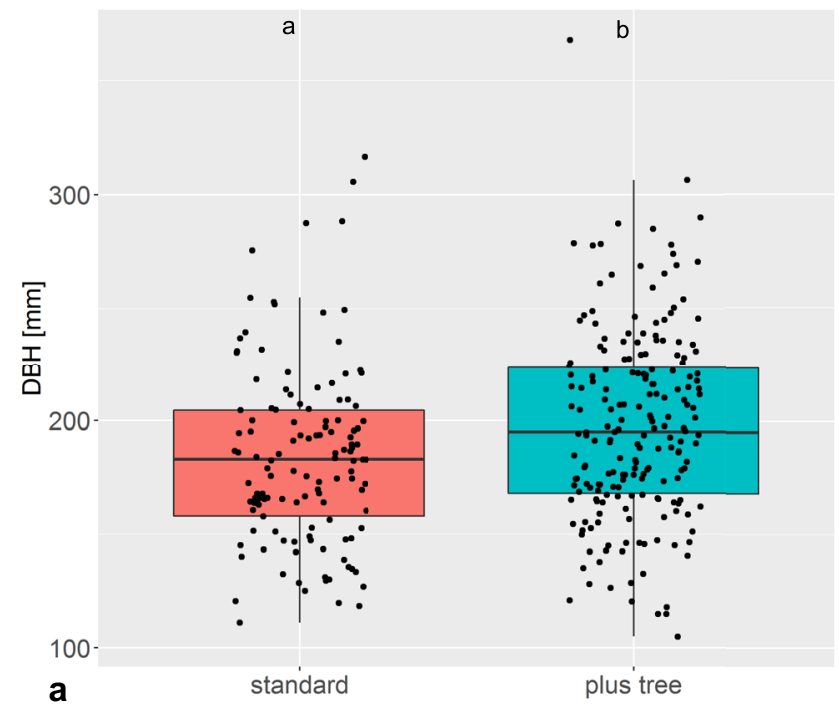

Fig. 8 Comparison of the groups "standard seed stands" and "plus tree mother" of the A. pseudoplatanus progeny trials Romrod and Schotten. a DBH. b Tree height. Boxplot with additional information

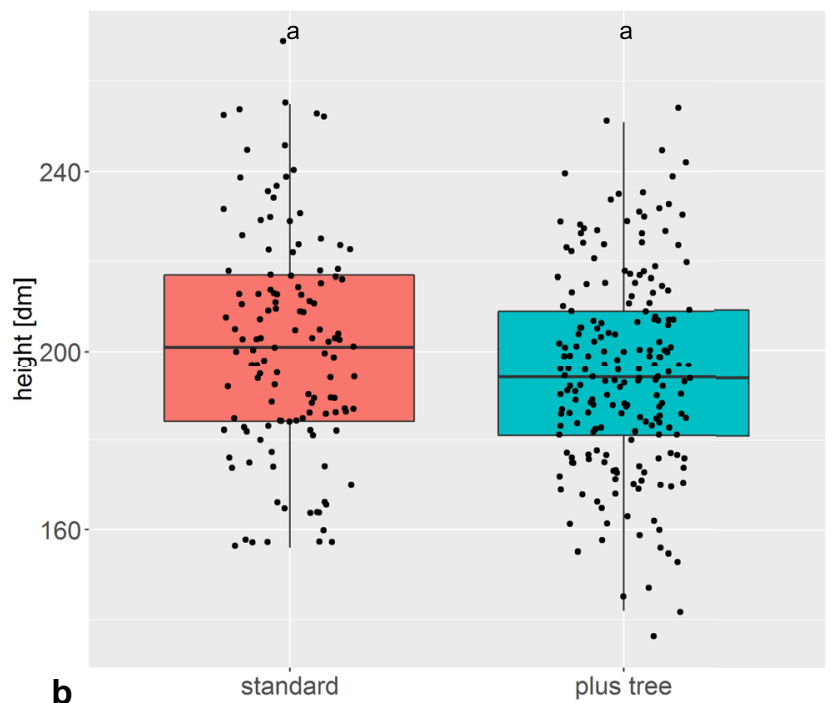

on single tree data (black dots). Different letters indicate significant differences in pairwise comparison of the groups (Tukey's test, limit $p<0.05) . n=$ standard 125 , plus tree 199 
Acknowledgments We thank Petra Knauer from the Thünen Institute for technical assistance during the genetic analysis and Tina Wetzel from the Northwest German Forest Research Institute for technical assistance during in vitro plant propagation. Special thanks to Dr. Christoph Stiehm for support and advice during statistical analysis.

Funding Open Access funding enabled and organized by Projekt DEAL. The research was funded by the Landwirtschaftliche Rentenbank, German Federal Ministry of Food and Agriculture.

Data availability The datasets generated during and/or analyzed during the current study are not publicly available due to the data sharing policies of participating institutions but are available from the corresponding author on reasonable request.

\section{Declarations}

Conflict of interest The authors declare that they have no conflict of interest.

Open Access This article is licensed under a Creative Commons Attribution 4.0 International License, which permits use, sharing, adaptation, distribution and reproduction in any medium or format, as long as you give appropriate credit to the original author(s) and the source, provide a link to the Creative Commons licence, and indicate if changes were made. The images or other third party material in this article are included in the article's Creative Commons licence, unless indicated otherwise in a credit line to the material. If material is not included in the article's Creative Commons licence and your intended use is not permitted by statutory regulation or exceeds the permitted use, you will need to obtain permission directly from the copyright holder. To view a copy of this licence, visit http://creativecommons.org/licenses/by/4.0/.

\section{References}

Bäucker C, Liesebach H (2018) From in vitro clones to high-quality timber production: the Project "Wavy Grain Maple." In: Degen B, Krutovsky KV, Liesebach M (eds) German Russian Conference on Forest Genetics. Johann Heinrich von Thünen-Institut, Braunschweig, pp 49-54

Beals HO, Davis TC (1977) Figure in wood: an illustrated review. Agricultural Experimant Station/Auburn University, Auburn, Alabama

Bragg DC (2006) Potential contributions of figured wood to the practice of sustainable forestry. J Sustain For 23:37-41. https:// doi.org/10.1300/J091v23n03

Bragg DC, Mroz GD, Reed DD, Shetron SG, Stokke DD (1997) Relationship between "birdseye" sugar maple (Acer saccharum) occurrence and its environment. Can J For Res 27:1182-1191

Conrad J (1988) Seltene, abnorme Holzstrukturen und-farben bei Laubhölzern. Die Holzzucht 42:1-9

Development Core Team R (2019) R: a language and environment for statistical computing. R Foundation for Statistical Computing, Vienna, Austria

Dumolin S, Demesure B, Petit RJ (1995) Inheritance of chloroplast and mitochondrial genomes in pedunculate oak investigated with an efficient PCR method. Theor Appl Genet 91:1253-1256. https:// doi.org/10.1007/BF00220937

Ewald D, Naujoks G (2015) Vegetative propagation of wavy grain Acer pseudoplatanus and confirmation of wavy grain in wood of vegetatively propagated trees: a first evaluation. Dendrobiol $74: 135-142$
Fan Y, Rupert K, Wiedenhoeft AC, Woeste K, Lexer C, Meilan R (2013) Figured grain in aspen is heritable and not affected by grafttransmissible signals. Trees - Struct Funct 27:973-983. https:// doi.org/10.1007/s00468-013-0849-1

Fox J, Weisberg S (2011) An R Companion to Applied Regression. Sage, Thousand Oaks (CA)

Graignic N, Tremblay F, Bergeron Y (2013) Development of polymorphic nuclear microsatellite markers in sugar maple (Acer saccharum Marsh.) using cross-species transfer and SSR-enriched shotgun pyrosequencing. Conserv Genet Resour 5:845-848. https:// doi.org/10.1007/s12686-013-9923-7

Hejnowicz Z, Romberger JA (1979) The common basis of wood grain figures is the systematically changing orientation of cambial fusiform cells. Wood Sci Technol 13:89-96

HessenForst (2017) Rekorderlöse auf Buntlaubholz- und Eichenwertholzsubmission in Jesberg. In: Holzverkauf und Holzpreise

Hynynen J, Niemistö P, Brunner A, Hein S, Velling P (2010) Silviculture of birch ( Betula pendula Roth and Betula pubescens Ehrh.) in northern Europe. For 83:103-119. https://doi. org/10.1093/forestry/cpp035

Jones OR, Wang J (2010) COLONY: a program for parentage and sibship inference from multilocus genotype data. Mol Ecol Resour 10:551-555. https://doi.org/10.1111/j.1755-0998.2009.02787.x

Kärkkäinen K, Viherä-Aarnio A, Vakkari P, Hagqvist R, Nieminen K (2017) Simple inheritance of a complex trait: figured wood in curly birch is caused by one semi-dominant and lethal Mendelian factor? Can J For Res 47:991-995

Kikuchi S, Shibata M (2008) Permanent genetic recources: Development of polymorphic microsatellite markers in Acer mono Maxim. Mol Ecol Resour 8:339-341. https://doi.org/10.1111/j. 1471-8286.2007.01948.x

Krabel D, Wolf H (2013) Sycamore Maple (Acer pseudoplatanus L.). In: Pâques LE (ed) Forest tree breeding in Europe: current state-of-the-art and perspectives, 25th edn. Springer-Science and Business Media, Dordrecht, pp 373-402

Krajnc L, Čufar K, Brus R (2015) Characteristics and geographical distribution of fiddleback figure in wood of Acer pseudoplatanus L. in Slovenia. Drv Ind 66:213-220. https://doi.org/10.5552/drind. 2015.1447

Lenth R (2019) emmeans: Estimated Marginal Means, aka LeastSquares Means. https://cran.r-project.org/package=emmeans

Mayer-Wegelin H, Pieper J (1959) Die Zeichnung von Furnierhölzern und ihre Beurteilung nach Merkmalen am Rundholz/ The texture of veneer woods and their evaluation by log characteristics. Holz als Roh- und Werkst 17:305-312

McKenna JR, Geyer WA, Woeste KE, Cassens DL (2015) Propagating figured wood in black walnut. Open J For 05:518-525. https://doi. org/10.4236/ojf.2015.55045

Naujoks G, Ewald D, Meier-Dinkel A, Wallbraun M (2013) Stand und Perspektiven der Forschung beim Riegelahorn. AFZ Der Wald 5:10-12

Pandey M, Gailing O, Fischer D, Hattemer HH, Finkeldey R (2004) Characterization of microsatellite markers in sycamore (Acer pseudoplatanus L.). Mol Ecol Notes 4:253-255. https://doi.org/10. 1111/j.1471-8286.2004.00633.x

Panshin AJ, De Zeeuw C (1980) Textbook of wood technology. Part 1. Formation, anatomy, and properties of wood. McGraw-Hill, New York, USA

Park B, Kwon S, Kwon G, Jang JH, Kim H (2010) Appearance pattern of figures in commercial domestic hardwoods ( I ). Mokchae Konghak 38:391-398

Pinheiro J, Bates D, DebRoy S, Sarkar D, R Development Core Team (2019) nlme: Linear and Nonlinear Mixed Effects Models. https:// cran.r-project.org/package $=$ nlme 
Richter C (2015) Wood characteristics: description, causes, prevention, impact on use and technological adaptation. Springer International Publishing, Switzerland

Rohr R, Hanus D (1987) Vegetative propagation of wavy grain sycamore maple. Can J For Res 17:418-420

Rusanen M, Myking T (2003) Technical guidelines for genetic conservation and use of Sycamore. Italy, Rome

Ryynänen L, Ryynänen M (1986) Propagation of adult curly-birch succeeds with tissue culture. Silva Fenn 20:139-147

Segarra-Moragues JG, Gleiser G, González-Candelas F (2008) Isolation and characterization of microsatellite loci in Acer opalus (Aceraceae), a sexually-polymorphic tree, through an enriched genomic library. Conserv Genet 9:1059-1062. https:// doi.org/10.1007/s10592-007-9451-7
Sopushynskyy I, Teischinger A (2013) Diagnostic features of Fraxinus excelsior L. with wavy-grained wood growing in Ukraine. For Res Pap 74:189-195. https://doi.org/10.2478/frp-2013-0018

Wang J, Scribner KT (2014) Parentage and sibship inference from markers in polyploids. Mol Ecol Resour 14:541-553. https://doi. org/10.1111/1755-0998.12210

Publisher's Note Springer Nature remains neutral with regard to jurisdictional claims in published maps and institutional affiliations. 